\title{
Numerical investigation of dimple-texturing on the turning performance of hardened AISI H-13 steel
}

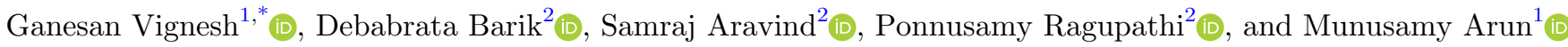 \\ ${ }^{1}$ Research Scholar, Department of Mechanical Engineering, Karpagam Academy of Higher Education, Coimbatore 641021 , \\ India \\ ${ }^{2}$ Department of Mechanical Engineering, Karpagam Academy of Higher Education, Coimbatore 641021 , India
}

Received: 10 January 2021 / Accepted: 29 November 2021

\begin{abstract}
Forming micro-dimples nearer to the cutting edge on the rack face of the tungsten carbide cutting inserts will positively influence the machinability. However, it is challenging to machine the perfect microdimple dimensions by utilizing the available machining techniques. Finite element analysis can be an efficient way to observe the influence of dimple-texture area density, micro-dimple size, and various micro-dimple shapes on cutting inserts' machinability. This paper numerically analyses the impact of micro-dimple-textured cutting inserts in dry machining of AISI H-13 steel using AdvantEdge (virtual machining and finite element analysis software). Micro-dimples are formed on the rack face of tungsten carbide cutting inserts to observe the effect of dimple-textured cutting inserts on machinability compared to non-textured cutting inserts in terms of microdimple shape, micro-dimple size, and micro-dimple area density ratio. Their outcomes are analysed in terms of chip-insert contact length, main cutting force, and thrust force. It is observed that micro-dimple textured cutting inserts exhibit minimal main cutting force and thrust force in line with increasing the cutting insert life span. The abrasive wear was reduced in dimple-textured cutting inserts due to minimal contact between the cutting insert and chip developed compared to non-textured cutting inserts.
\end{abstract}

Keywords: Dimple-textured cutting insert / FEM analysis / cutting force / abrasive wear / dimple area density

\section{Introduction}

In past decades, the tool wear was controlled by applying cutting fluids and by various surface coating techniques. But considering the economic factor in machining, environmental protocol against cutting fluids, and health factors, dry machining becomes a need of the day. In dry machining of metal using tungsten carbide inserts, severe wear can be observed on the cutting tool's rack face. The chip continuously flows over the rack face and causes an increment in the tool-chip contact area resulting in crater wear on the rack face. Different sustainable dry machining methods like insert surface modification, minimum/low quantity lubrication (MQL/LQL), micro-MQL, nano-MQL, and cryonic cooling have been applied for dry machining hardened steels, Inconel, and titanium alloys [1,2].

Recently, dimple-textured inserts have been identified as potential dry machining techniques. Dimple-texture tools exhibit a more significant influence in friction and/or wear reduction due to reduced tool-chip tribo-contact area.

\footnotetext{
* e-mail: gvcit2008@gmail.com
}

Duan et al. [3] made a comparative study on regular cutting tools and dimple-texture cutting tools and observed that cutting forces and energy consumption were reduced in dimple-texture cutting tools due to dimple-texture with race face exhibits sufficient lubricity. Durairaj et al. [4] conducted dry machining of aluminium using a circular shape dimpletexture tool with different dimensions and reported that dimple-textures formed parallel to the rack's cutting-edge face were efficient. The adhesion or deposition of the aluminium on the cutting tool was $15 \%$ lower than that of the plain tool. FEM simulations explored the fact that dimple-textures affect the stress concentration in the cutting inserts. The overall values of strains and stresses of dimple-textured cutting inserts were within the safe limits. Compared to regular insert, $7.31-17.41 \%$ of cutting force reduction was observed in mechanically micro-textured tools [5].

Dry machining tests were conducted to systematically analyze the cutting performance of dimple-texture tools interms of cutting force, tool-burr adhesion, chip morphology, and abrasion wear at the rack face. In dry machining with dimple-textured tools, the friction and main cutting forces were reduced by $15 \%$ and $10 \%$, respectively, compared to non-textured tools [6]. Khan and Gupta [7] 
found that cutting speed and feed rate are significant factors for machining time and insert life. Based on the Taylor equation, it is understood that the insert life is maximum with low cutting speed and minimum with high cutting speed. Lian et al. [8] conducted a dry cutting test on AISI-1045 steel using the coated textured tool. The results specified that, the main cutting force of the coated textured tool was $18.8 \%$ lower than an uncoated non-textured tool. Liu et al. [9] adopted Advantedge software to analyze the effect of micro-grooved tools on-chip curling, wear rate, chip thickness, cutting temperatures, and forces. Per their results, linear micro-grooved inserts were efficient in stress distributions and reduced stress concentration, which is beneficial for developing micro-grooved tools. The specific machining energy can be defined as the energy consumption of material removal per unit volume. It was observed that the particular machining energy was reduced in curvilinear dimple-textures by limiting the tool-burr contact area and minimizing the cutting forces [10]. Ma et al. [11] numerically investigated the dry machining of AISI 1045 steel with dimple-textured inserts and found that the cutting and thrust forces were not influenced by the starting distance of the dimples from the cutting edge. At higher feed rates, finite element simulation outcomes of overall cutting force are significantly nearer to experimental results [12]. As material is machined from the work piece, the minimal essential clamping forces are observed to reduce [13].

In dry machining, the shape of the dimple-textures over the cutting inserts influences the main and thrust cutting forces. Still, dimple area density is the most significant parameter to reduce cutting force and temperature to a greater extent. There is minimal or no effect of dimple depth on cutting force due to no fluid involvement in dry cutting [14]. Mishra et al. [15] applied finite element simulations to understand the effect of uncoated and coated texture tools for dry machining of Ti6Al4V. They identified that textured tools could separate the burrs from the tool-work interface and result in highly finished surfaces. Sawant et al. [16] studied the influence of using dot-textured HSS tools in machining titanium alloy, reduced cutting forces, cutting temperature, wear rate, and surface roughness machined workpiece than regular HSS tool at different cutting speed. Dots in the dottextured HSS tool can act as heat transfer fins, which improve the convective heat transfer to the cutting fluid and/or the environment.

Singh et al. [17] reported that the overall machining performance was improved with a dimple-textured tool by reducing the tool-burr contact length and area and storing the cutting fluid supplies on the rack face. Vignesh et al. [18] suggested that wear and/or friction reduction outcomes were more significant in ellipticalshaped dimples followed by hemispherical and triangular dimples. Vignesh et al. [19] recommended that microdimple size of $90 \mu \mathrm{m}$, the pitch of $135 \mu \mathrm{m}$, depth of $60 \mu \mathrm{m}$, and area density of $35 \%$ be preferred based on wear test. Wei et al. [20] observed that the micro dimples' shape had a more significant influence on tribological improvements in cutting inserts. Circular shapes dimples have superior potential to be fabricated on a large scale in the view of the dimple-texturing process's economic feasibility. Zhang et al. [21] found that the dimple-texture on the insert rack face exhibits a more significant reduction in cutting force and friction co-efficient between tool-work tribo-contact surfaces down the wear rate and positively influence the chip morphology. The fabrication of dimple-texture reduces the tool-burr contact area and length, results in minimal heat generation at the tribocontact zone. The dimple-texture can store the metal debris and minimize the abrasive wear in the tool-work tribo-contact area.

In this research work, the virtual machining and finite element analysis software AdvantEdge is used to analyze the influence of dimple-texture cutting tools in dry machining of AISI H-13 steel. Initially, numerical evaluation outcomes are compared with the experimental one to approve the numerical model. An extensive analysis is then made to observe the dimple-texture parameters (microdimple shape, micro-dimple size, and micro-dimple area density ratio) on machining temperature and cutting force. This research helps to identify the optimal parameters of micro-dimples to improve the tool life and reduce the specific cutting energy.

\section{2D FE simulation}

AdvantEdge virtual machining and finite element analysis software have been utilized to numerically analyze AISI H-13 steel machining using non-textured and dimpletextured tungsten carbide inserts. For validation purposes, finite element (FE) simulation results are compared with experimental trials. AdvantEdge software uses explicit dynamic code, and an adaptive meshing technique was used for meshing of insert, workpiece, and chip. Standard 4-node, 12 DOF tetrahedral elements were used in the tool, and workpiece's finite element model. The maximum and minimum finite element sizes were set as $0.1 \mathrm{~mm}$ and $0.01 \mathrm{~mm}$, respectively, for both tool and workpiece. The left end and base of the work piece were constrained, and the cutting insert was advanced in a positive direction. The ALE technique of finite element formulation and the mesh refinement were done on the cutting insert using an adaptive convergence technique based on iterations. The current 2D FE simulations involve machinability study of non-textured and dimpletextured tungsten carbide cutting tools under dry machining of AISI H-13 steel.

\subsection{Workpiece modeling}

AISI H-13 steel of $15 \mathrm{~mm} \times 3 \mathrm{~mm}$ dimensions is selected as a work material with the boundary conditions: 1. work material bottom fixed in the y-direction (FixY), 2. work material left side fixed both $\mathrm{x}, \mathrm{y}$ directions (FixXY). The insert's linear movement achieves the relative motion between the work material and inserts at the predefined machining speed. The Johnson-Cook (J-C) model is applied to understand the work material behavior. The properties of the $\mathrm{J}-\mathrm{C}$ model for AISI H-13 steel are listed in Table 1, and the $\mathrm{J}-\mathrm{C}$ model for current simulation in 
Table 1. Properties of work material.

\begin{tabular}{llll}
\hline Element name & Chemical composition (\%) & Mechanical properties & Values \\
\hline $\mathrm{Cr}$ & $4.75-5.50$ & Tensile Strength (MPa) & $1200-1590$ \\
$\mathrm{Mo}$ & $1.10-1.75$ & Yield Strength (MPa) & $1000-1380$ \\
$\mathrm{~V}$ & $0.80-1.20$ & Impact Strength (J) & $60-74$ \\
$\mathrm{Si}$ & $0.80-1.20$ & Hardness (BHN) & $290-370$ \\
$\mathrm{C}$ & $0.32-0.45$ & Elongation (\%) & 11 \\
$\mathrm{Cu}$ & 0.25 & & \\
$\mathrm{Ni}$ & 0.3 & & \\
$\mathrm{Mn}$ & $0.20-0.50$ & & \\
$\mathrm{~S}$ & 0.03 & & \\
$\mathrm{P}$ & 0.03 & & \\
\hline
\end{tabular}

Table 2. Properties of cutting insert.

\begin{tabular}{llll}
\hline Element name & Chemical composition (\%) & Mechanical properties & Values \\
\hline $\mathrm{W}$ & Balance & Tensile strength (MPa) & $370-530$ \\
$\mathrm{C}$ & $4.8-5.6$ & Yield strength (MPa) & $600-686$ \\
$\mathrm{Ni}$ & $8.5-11.5$ & Impact strength (J) & $482-820$ \\
$\mathrm{Cr}$ & $4.4-5.6$ & Hardness (BHN) & $420-480$ \\
$\mathrm{Fe}$ & $<0.3$ & Elongation (\%) & 8 \\
\hline
\end{tabular}

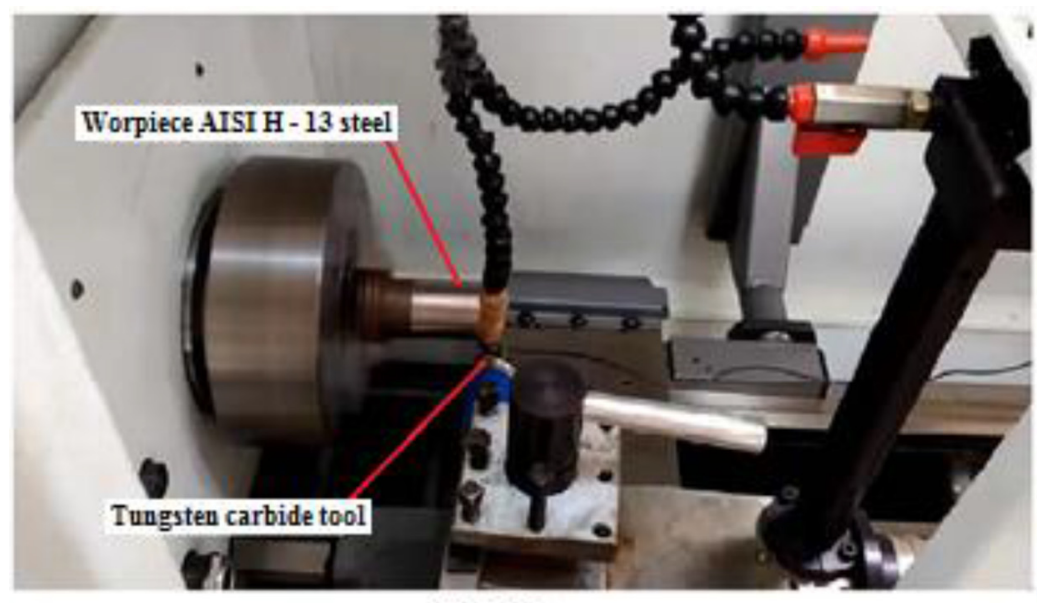

CNC lathe

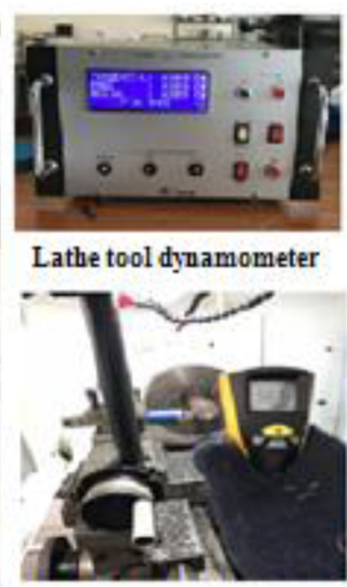

Temperature measurement

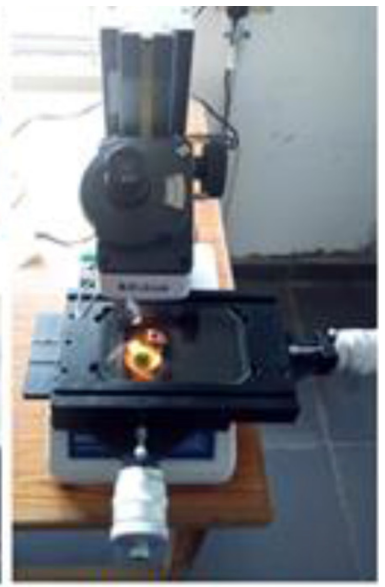

Optical microscope

Fig. 1. Machining setup.

expressed as

$$
\sigma_{E}=\left[\sigma_{Y}+H \varepsilon^{n}\right]\left[1+C_{s} \ln \left(\frac{\dot{\varepsilon}}{\dot{\varepsilon}_{R}}\right)\right]\left[1-\left(\frac{T-T_{o}}{T_{M}-T_{o}}\right)^{m}\right]
$$

where $\sigma_{E}$ refers to stress equivalent, $\sigma_{Y}$ refers to primary yield stress, $\mathrm{H}$ refers to hardness modulus, $\varepsilon$ refers to permeant strain, $C_{s}$ refers to the coefficient of strain rate, $\dot{\varepsilon}$ refers to the rate of strain, $\dot{\varepsilon}_{R}$ refers to the reference rate of strain, $T$ refers to machining temperature, $T_{o}$ refers to ambient temperature, $T_{M}$ refers to material melting temperature, and $m$ refers to the coefficient of thermal softening. Based on the Coulomb law of friction, the equation for the coefficient of friction $(\mu)$ is given by

$$
F=\mu \times F_{N}
$$

where $F$ refers to frictional force opposing the relative motion, $F_{N}$ normal applied load on the tribo-contact surfaces. The coefficient of friction of 0.86 is set in the AdvantEdge software obtained from the measured experimental forces. 
Table 3. Dimple-texturing parameters.

\begin{tabular}{|c|c|c|c|}
\hline Dimple properties & & Texture Name & \\
\hline Texture pattern & Non-textured & Circular dimples & Triangular dimples \\
\hline Structure of dimples & & & \\
\hline Pitch, $\mu \mathrm{m}$ & - & $135,150,165$ & $135,150,165$ \\
\hline Size of Dimples, $\mu \mathrm{m}$ & - & $90,120,150$ & $90,120,150$ \\
\hline Designation & NT & DT90C, DT120C, DT150C & DT90T, DT120T, DT150T \\
\hline Dimple depth, $\mu \mathrm{m}$ & - & 20 & 20 \\
\hline Dimple area density, \% & - & $25,35,45$ & $25,35,45$ \\
\hline Distance from the cutting edge, $\mu \mathrm{m}$ & - & 370 & 370 \\
\hline
\end{tabular}

Table 4. Machining conditions.

\begin{tabular}{ll}
\hline Workpiece & AISI H-13 steel \\
& $15 \mathrm{~mm} \times 3 \mathrm{~mm}$ \\
\hline Cutting Insert & Tungsten carbide insert \\
& Nose radius $-0.02 \mathrm{~mm}$ \\
& Rack angle $-5^{\circ}$ \\
Cutting speed (N) & Clearance angle $-6^{\circ}$ \\
Depth of cut (d) & $120 \mathrm{~m} / \mathrm{min}$ \\
Feed rate (f) & $2 \mathrm{~mm}$ \\
Machining condition & $0.3 \mathrm{~mm} / \mathrm{rev}$ \\
\hline
\end{tabular}

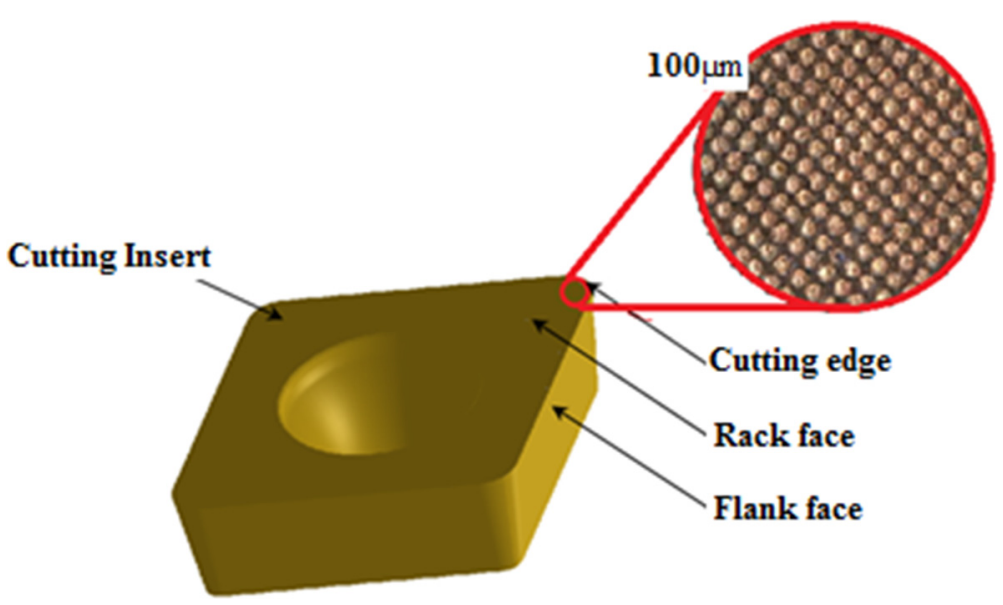

Fig. 2. Cutting insert with dimple-patterns.

\subsection{Cutting insert modelling}

Tungsten carbide is selected as a cutting tool material with the boundary conditions: 1 . tool top fixed in $\mathrm{x}$, $\mathrm{y}$ directions (FixXY), 2. tool left side fixed in both $\mathrm{x}$, $\mathrm{y}$ directions
(FixXY). Two micro-dimples (circular and triangular shape) with different dimensions are designed on the rack face of the cutting insert. The chip breakage mode enabled in Advantedge software to understand the insert behavior and tungsten carbide insert properties listed in Table 2. 

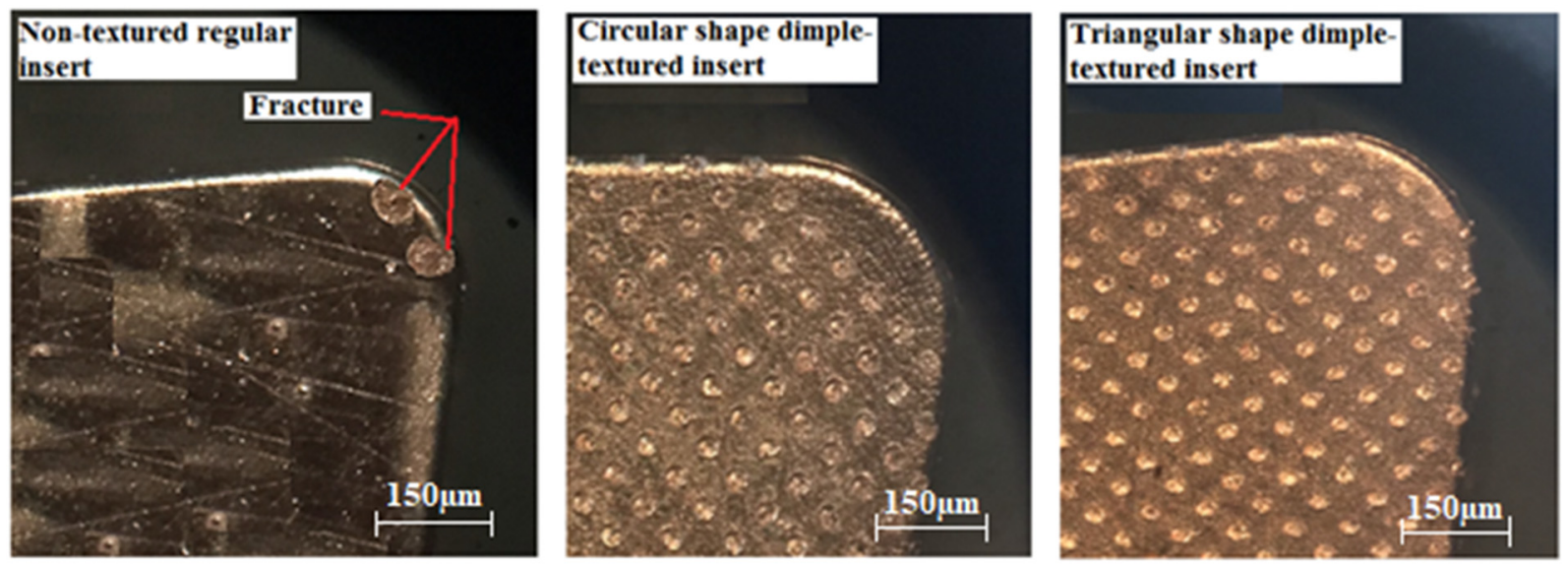

Fig. 3. Microscopic images of cutting inserts.

To enhance the FE simulations, all the flat edges are filleted using small radii of curves ranging from 0.05 to $0.10 \mathrm{~mm}$ based on the micro-dimples' size. Table 3 lists the dimple-texture parameters designed on the rack face of the cutting insert. FE simulations are performed with three values of micro-dimple shape, three values of microdimple size, and compared with a non-textured one. It should be noted that many researchers identified that dimple depth and linear distance between cutting edge and micro-dimples are not an influencing parameter, so we kept dimple depth as a constant for all the dimple-texture insert design. Furthermore, the dimple pitch and dimple area density change proportionally with the dimple size, so dimple area density is not an individual parameter in this work. The virtual room temperature for the FE simulation is set as $20^{\circ} \mathrm{C}$, and the machining conditions are listed in Table 4.

\section{Experimental methodology}

Dry machining test using non-textured and various kinds of dimple texture inserts are conducted using All geared conventional lathe. Figure 1 details the machining setup. A lathe tool dynamometer is employed to measure the three components of cutting forces. An optical microscope is used to examine the insert wear rate after machining all samples. The experimental machining conditions are identical in the FE simulation (Tab. 4) for validating the developed FE model. The two kinds of dimples with different dimensions are fabricated on the rack face of the cutting insert using the laser ablation technique. Figure 2 details the cutting insert with surface morphology of the dimple-patterns. The cutting length is maintained as $50 \mathrm{~mm}$ for all the insert samples.

Figure 3 shows the microscopic images of the nontextured regular tool, circular shape dimple-textured tool, and triangular shape dimple-textured tool after performing the dry turning experiment on AISI H-13 steel. The abrasive wear is observed in the tungsten carbide inserts' rack face due to continuous contact of burrs on the inserts and excessive heat generation. Compared to non-textured regular inserts, dimple-texture inserts exhibit a more significant influence on reducing tool wear due to a minimized tool-burr tribo-contact area.

Three components of cutting forces (Feed force, $F_{f}$; Thrust force, $F_{t}$; Cutting force, $F_{c}$ ) generated during dry machining experiments are measured with lathe tool dynamometer and converted to two components of orthogonal cutting forces (Main cutting force, $F_{X}$; Thrust force, $F_{Y}$ ) using equations (3) and (4).

$$
\begin{gathered}
F_{X}=F_{c} \\
F_{Y}=\sqrt{\left(F_{f}^{2}+F_{t}^{2}\right)} .
\end{gathered}
$$

The two components of orthogonal cutting forces from the dry machining experiments are compared with the FE simulation outcomes. The average values of the cutting forces are compared in both experimental and FE simulation experiments. In both cases, dimple-texture inserts exhibit lower cutting forces than non-textured regular inserts due to minimal tribo-contact between the tool-burr interfaces. Figure 4 compares the variation in cutting forces between experimental and FE simulation analyses for various dimple shapes and sizes. It clearly shows that, main cutting force, $F_{X}$ and thrust force, $F_{Y}$ have a good relationship between the experimental and FE simulations, and the deviation rate is observed within $10 \%$.

Cutting temperature generation at the tool-work interfaces during dry machining experiments are measured with an infrared thermometer and compared with the FE simulation outcomes to validate the developed FE models. In both cases, minimal heat generation is observed in the dimple-texture tool due to the micro-dimples' concave surface profile enhancing the faster heat dissipation. Figure 5 compares the variation in peak cutting temperature between experimental and $\mathrm{FE}$ analysis for various dimple shapes and sizes. It clearly shows that peak cutting temperature has a good relationship between the experimental and FE simulations, and the deviation rate is observed within 8\%. Furthermore, $120 \mu \mathrm{m}$ size circular-shaped 


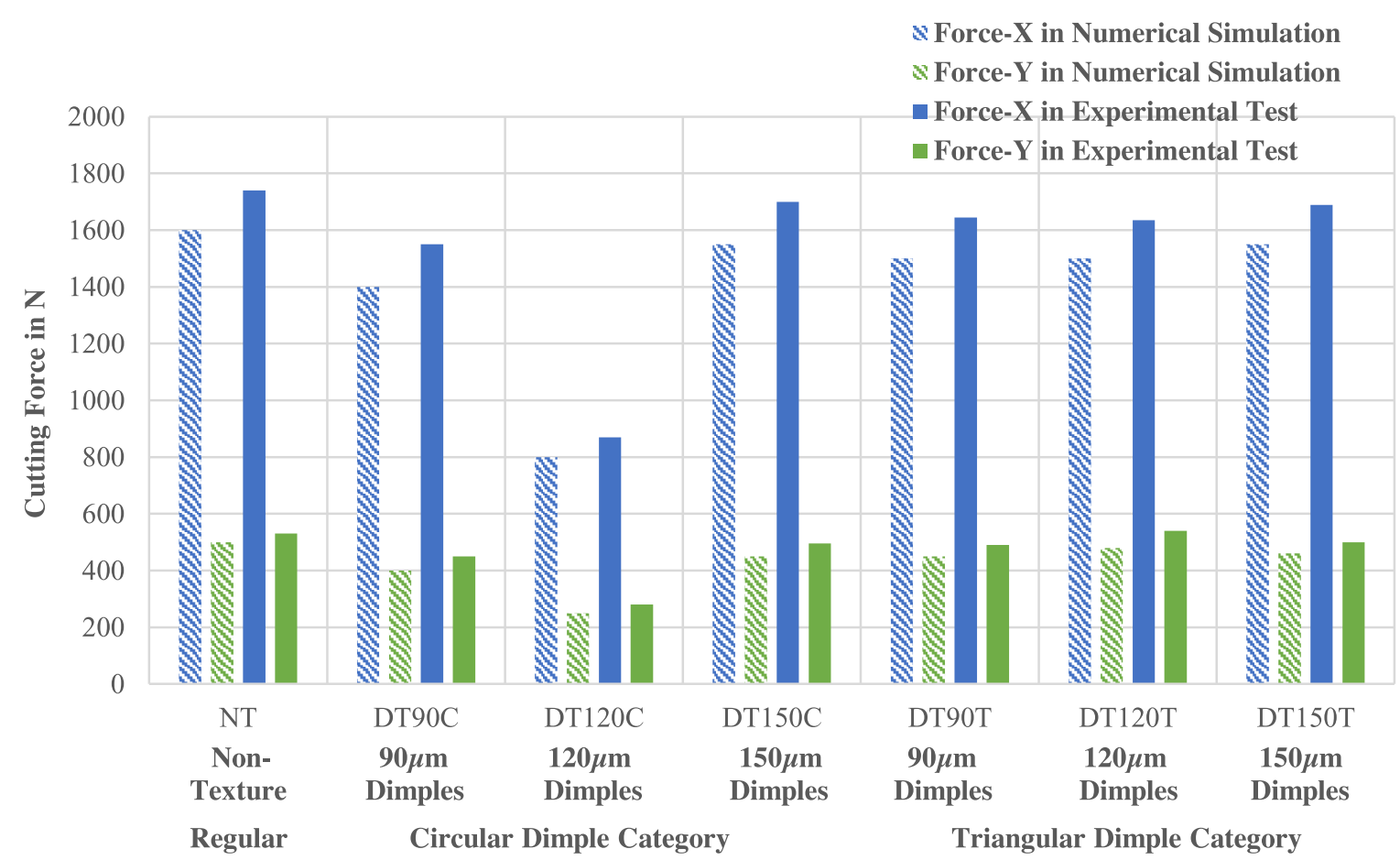

Fig. 4. Cutting force variation with various inserts.

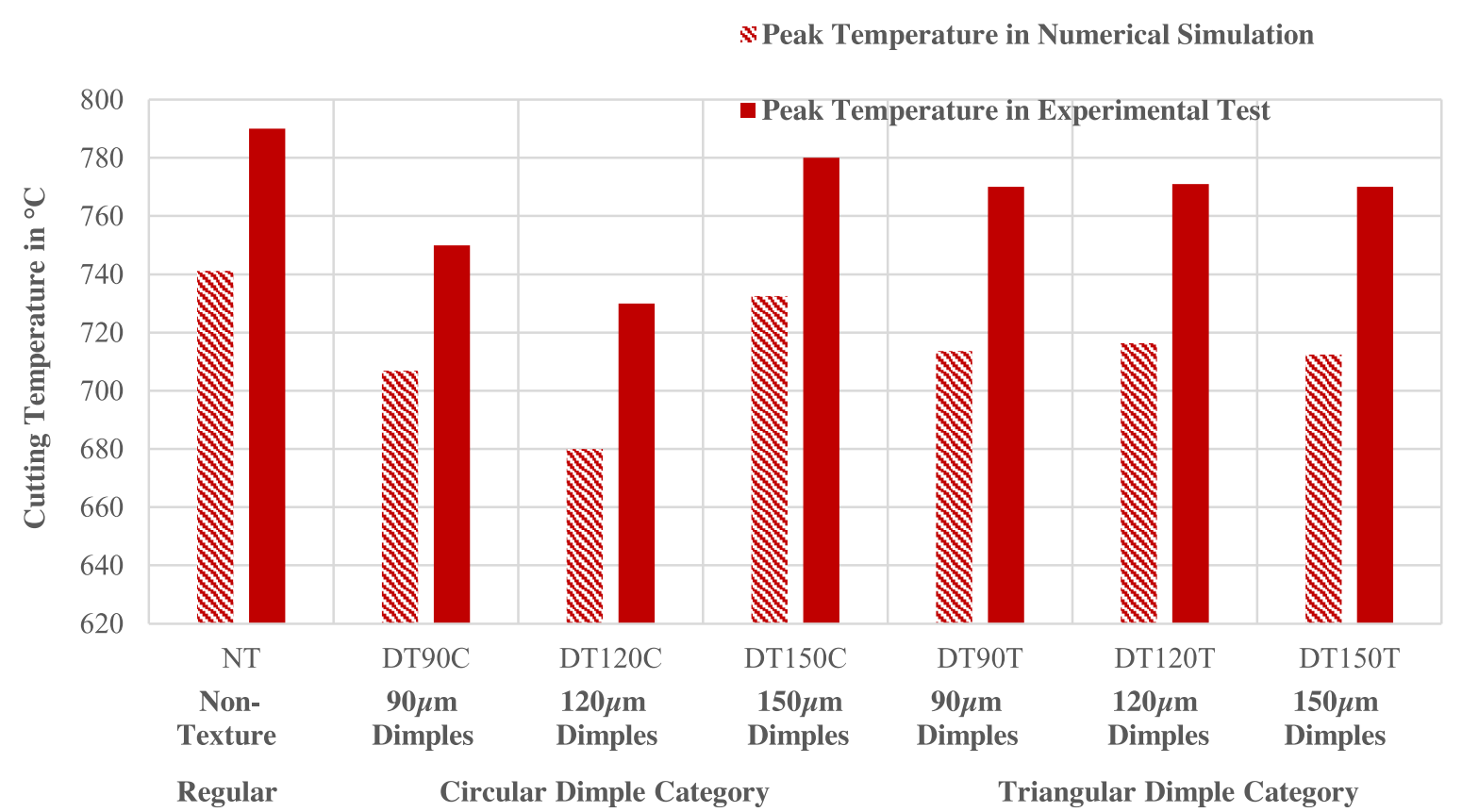

Fig. 5. Cutting temperature variation with various inserts. 


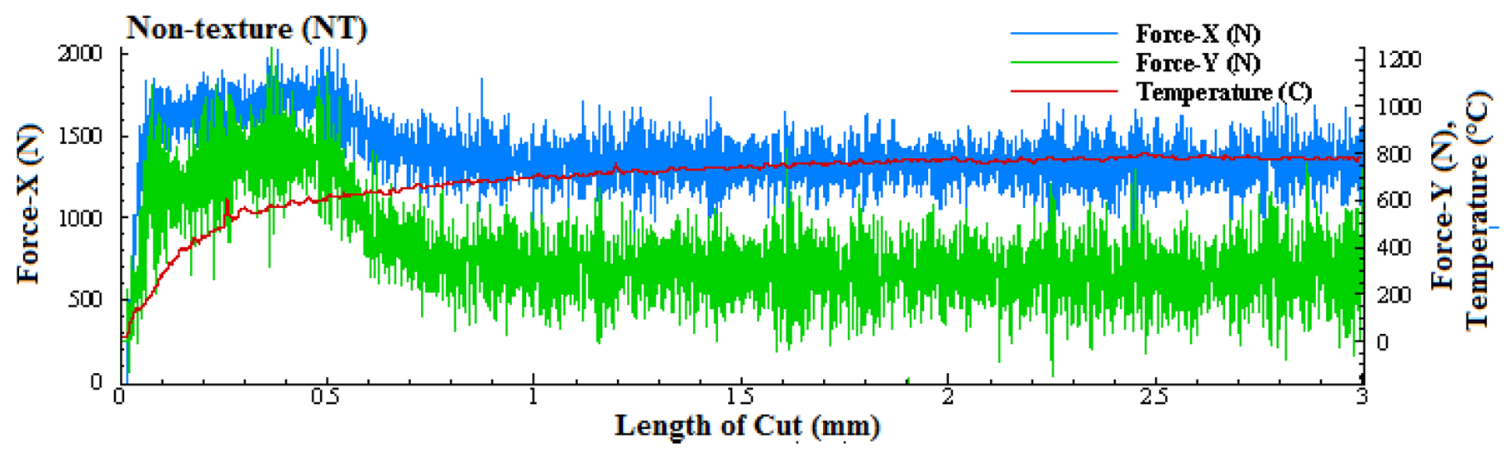

(a)

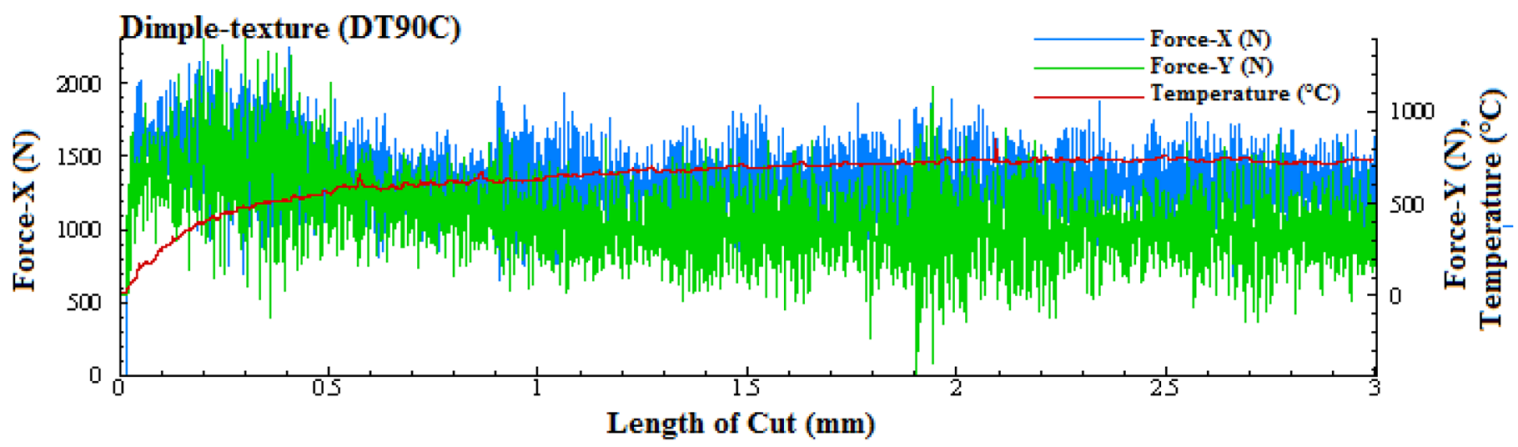

(b)

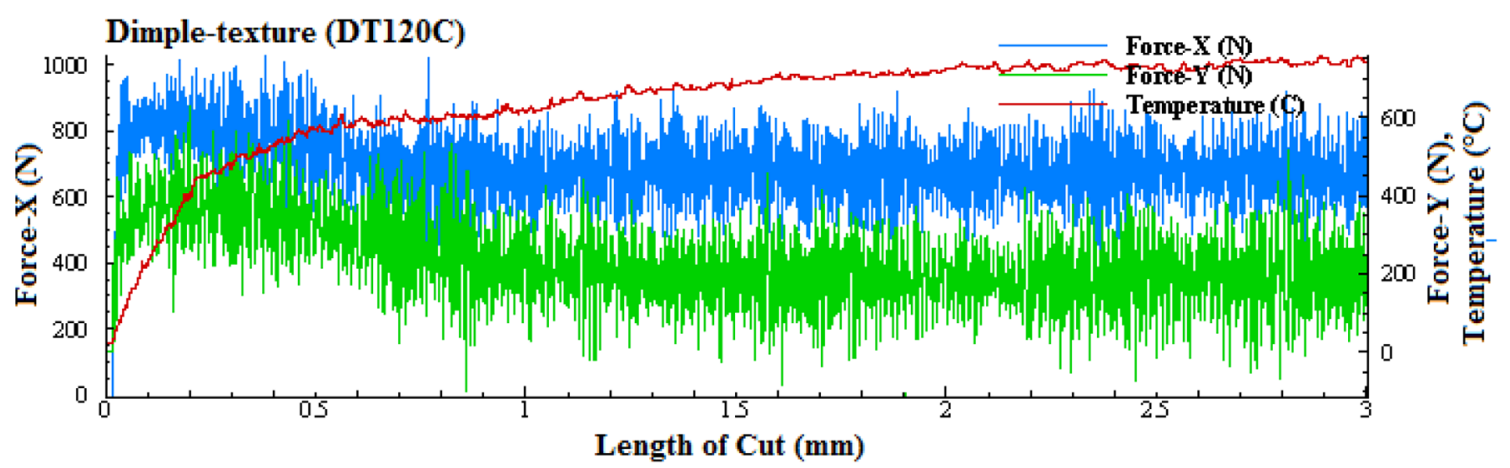

(c)

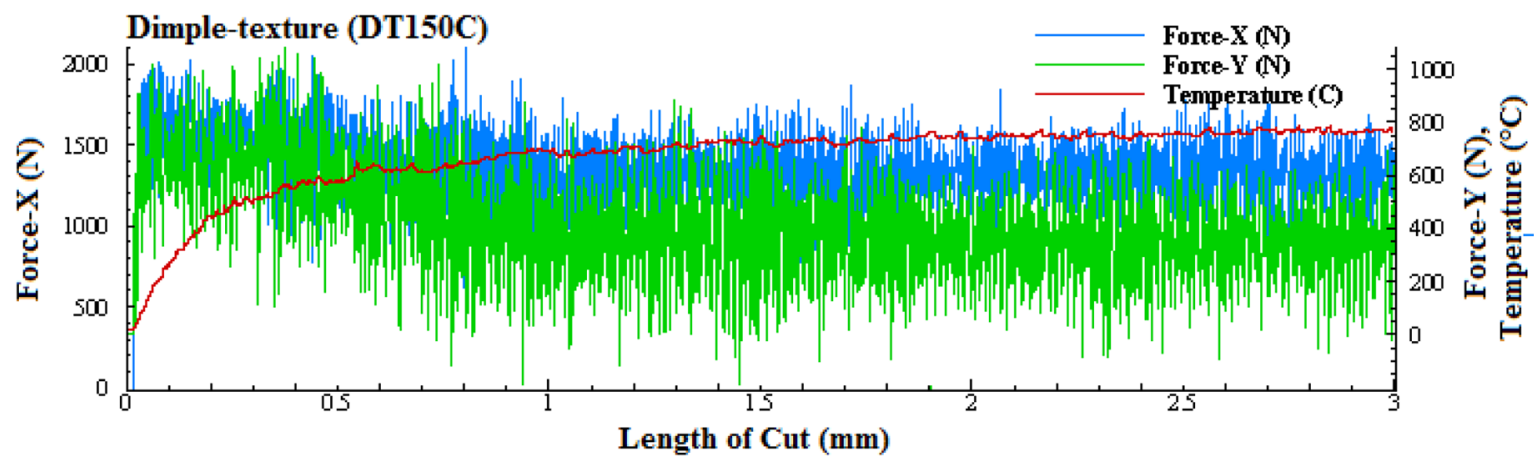

(d) 


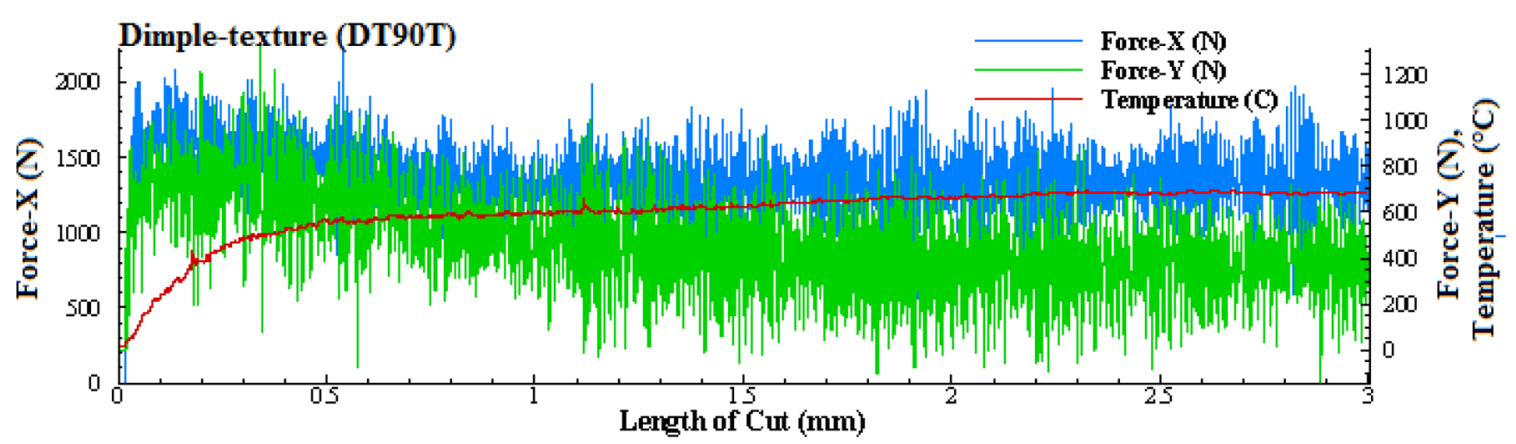

(e)

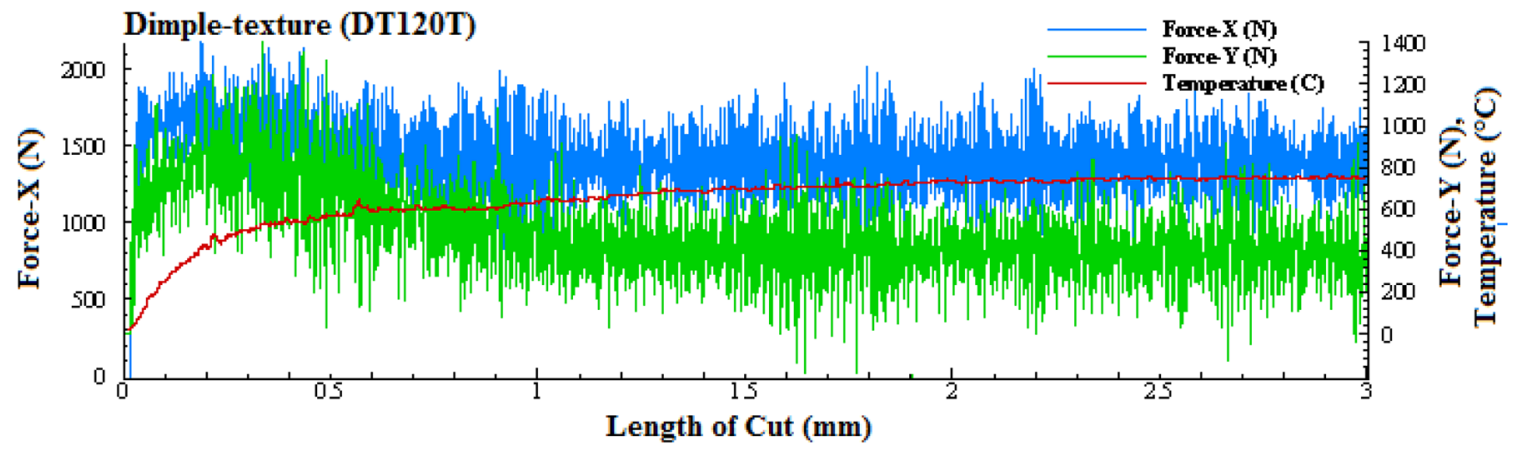

(f)

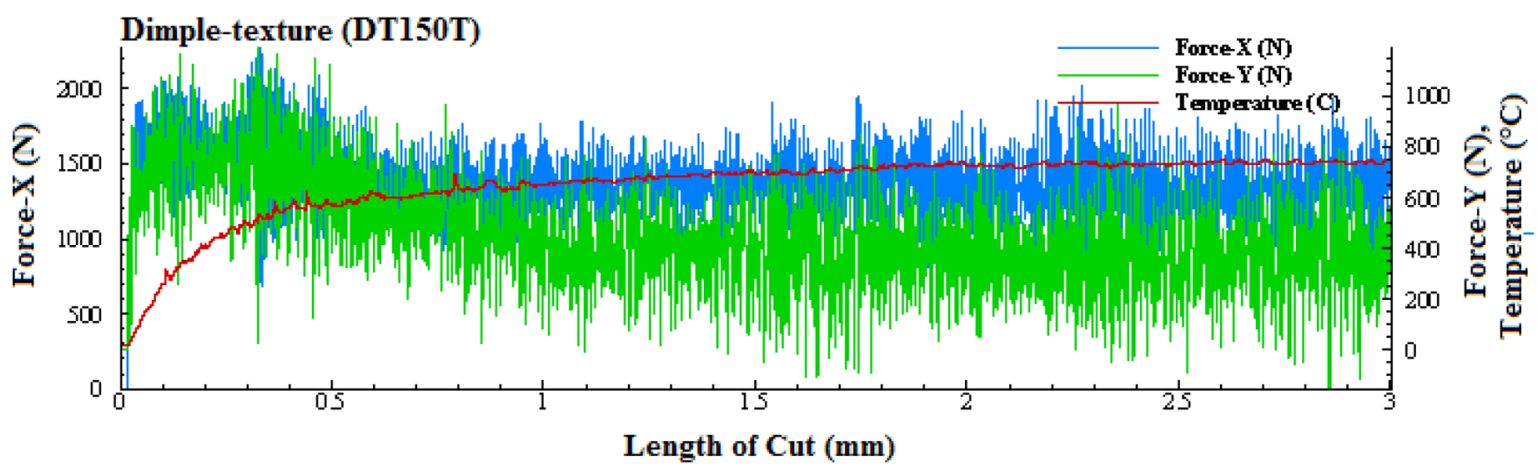

(g)

Fig. 6. Time histories of cutting forces and cutting temperature for various inserts. (a) Non-texture regular insert. (b) 90 um circular dimple-texture insert. (c) $120 \mu \mathrm{m}$ circular dimple-texture insert. (d) $150 \mu \mathrm{m}$ circular dimple-texture insert. (e) $90 \mu \mathrm{m}$ triangular dimple-texture insert. (f) $120 \mu \mathrm{m}$ triangular dimple-texture insert. (g) $150 \mu \mathrm{m}$ triangular dimple-texture insert.

dimple-textured inserts show much better performance in cutting force and cutting temperature reduction than all other inserts in both FE simulation and experimental test categories. It is clearly showing that the optimal shape and size of the micro-dimples to be fabricated on the rack face of the tungsten carbide inserts.

The cutting forces and cutting temperature generated during dry machining from the FE simulations and experimental tests are compared in Figures 4 and 5 for the dimple-textured and non-textured regular inserts. It can be observed that the cutting forces and the cutting temperature have a good relationship between the experimental test and FE simulations. Based on observations made in Figures 4 and 5, the developed FEM model can be validated and used to simulate AISI H-13 steel's dry machining with sufficient accuracy. Furthermore, micro-dimples stress distribution and maximum shear stress can be analysed through validated FE models and are not possible in experimental tests.

\section{Results and discussion}

The influence of micro-dimple shape and size on dry machining performance through $\mathrm{FE}$ simulation of turning AISI H-13 steel. The main cutting force (Force-X), thrust force (Force-Y), cutting temperature, von-mises stresses, and maximum shear stresses are recorded for each simulation. Figures 6-9 show the time histories of cutting forces, heat generation at tribo-contact surfaces, stress distribution, and maximum shear stress, respectively, for several FE simulations. 


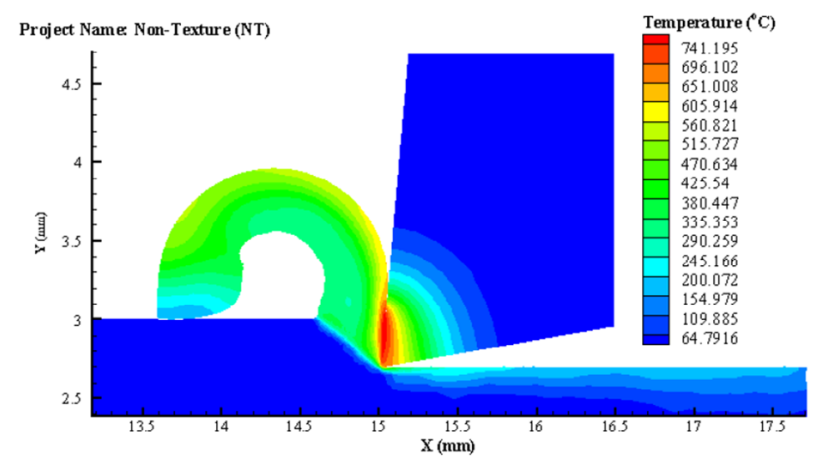

(a)

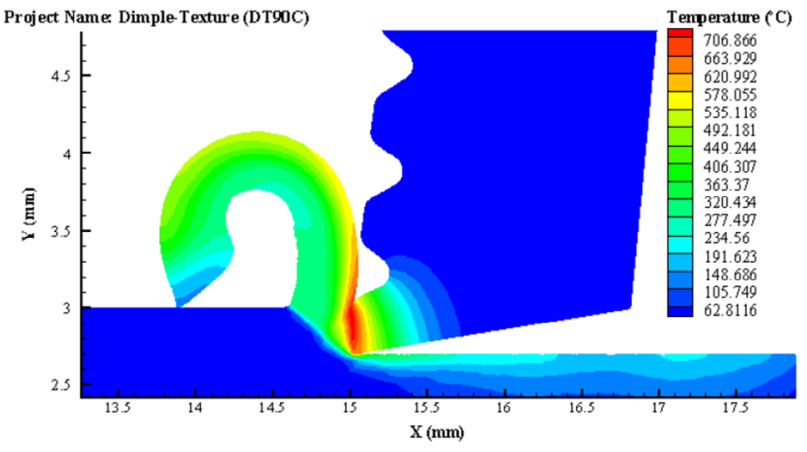

(b)

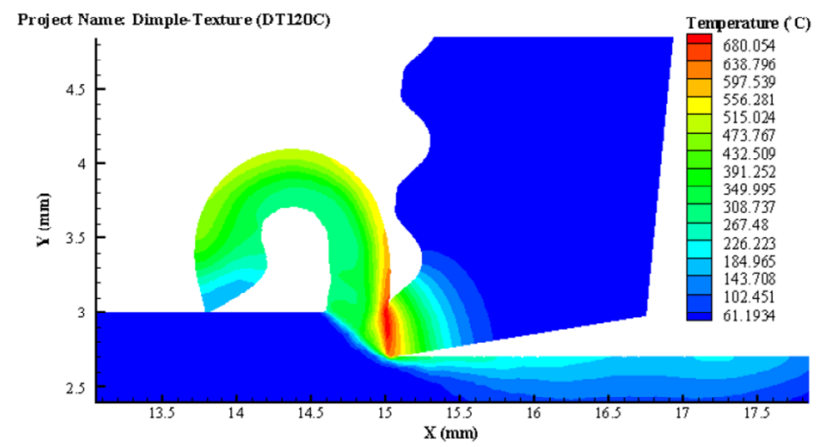

(d)

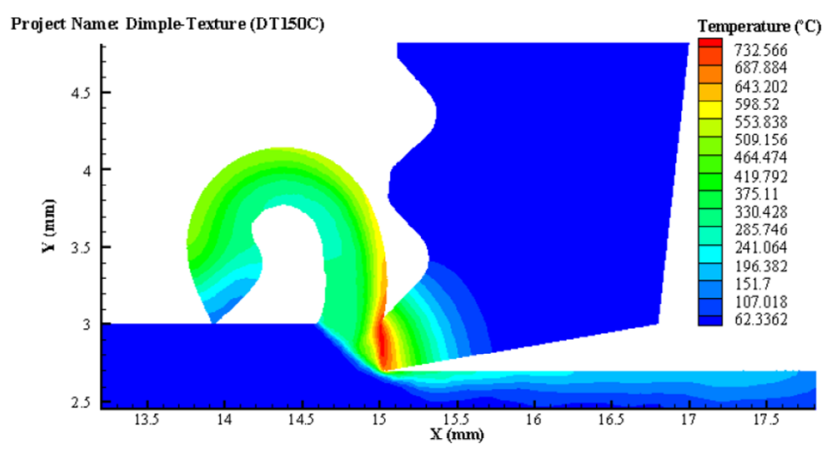

(f)

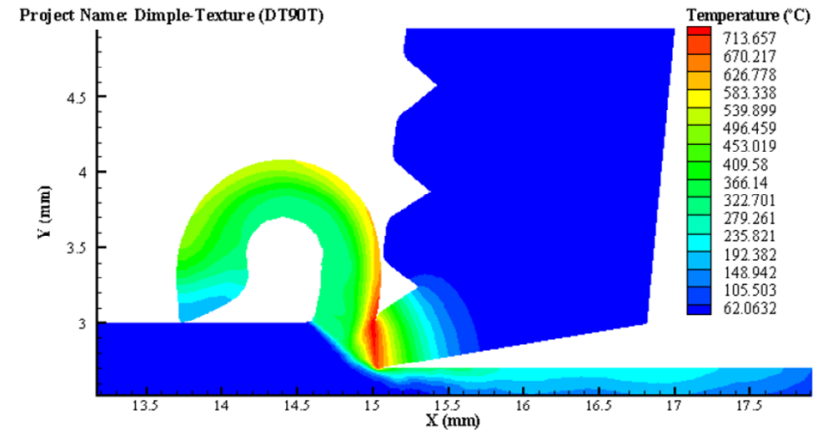

(c)

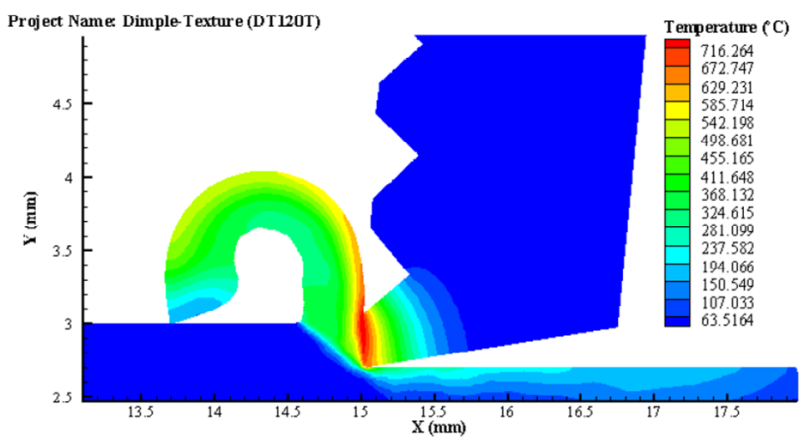

(e)

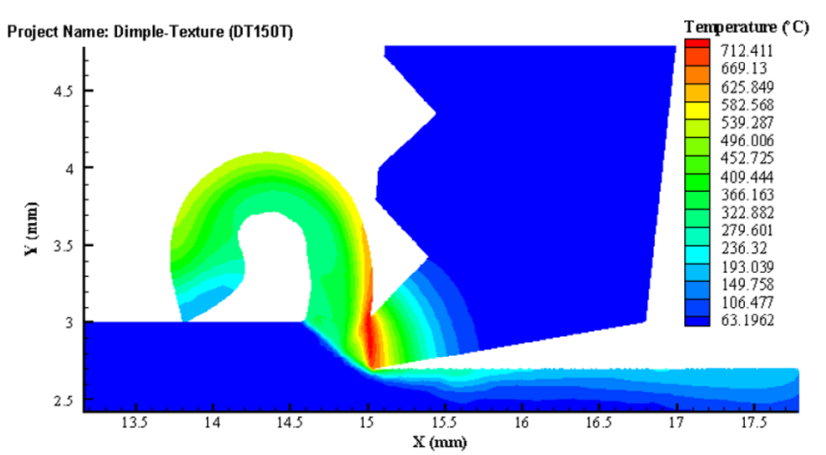

(g)

Fig. 7. Heat generation at tribo-contact surfaces for various inserts. (a) Non-texture regular insert. (b) $90 \mu \mathrm{m}$ circular dimple-texture insert. (c) $90 \mu \mathrm{m}$ triangular dimple-texture insert. (d) $120 \mu \mathrm{m}$ circular dimple-texture insert. (e) 120 m triangular dimple-texture insert. (f) $150 \mu \mathrm{m}$ circular dimple-texture insert. (g) $150 \mu \mathrm{m}$ triangular dimple-texture insert. 


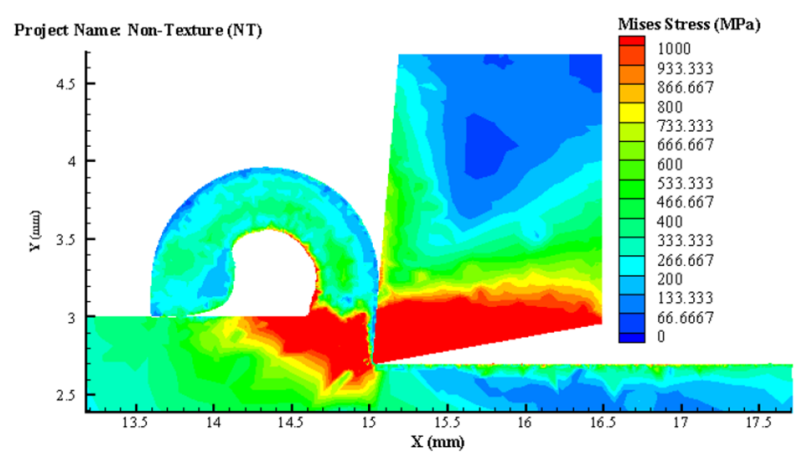

(a)

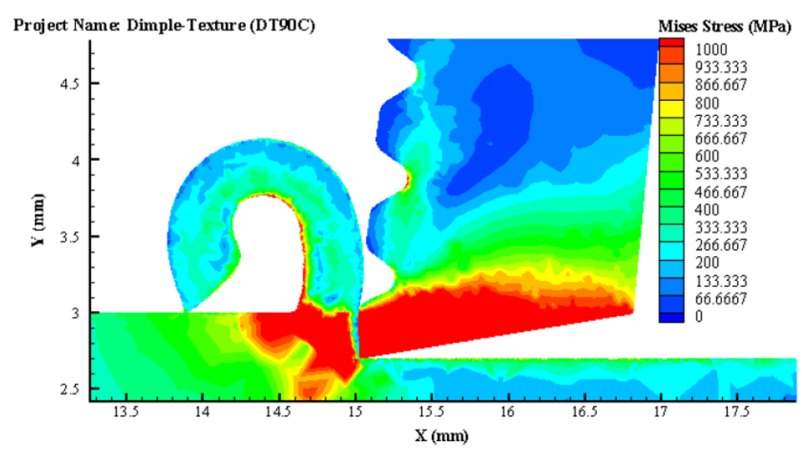

(b)

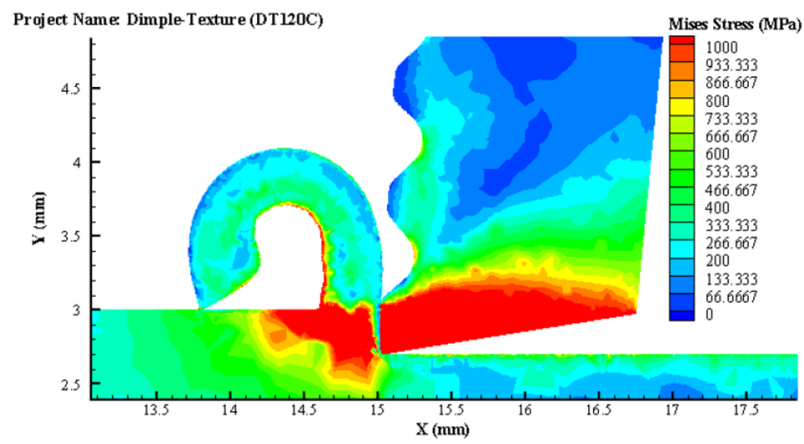

(d)

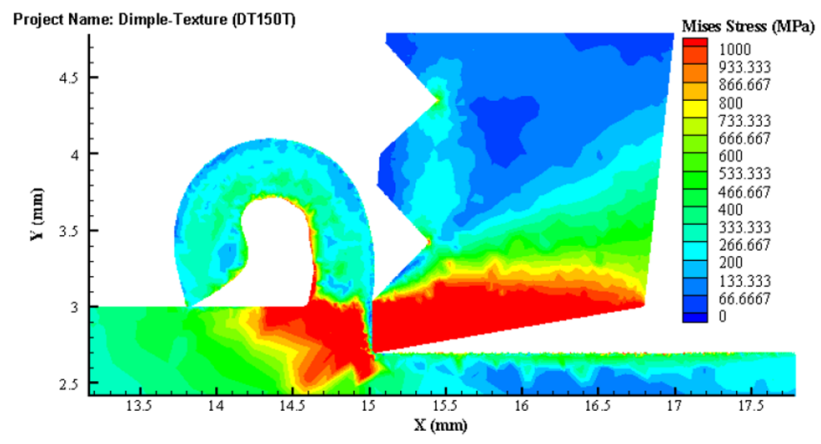

(f)

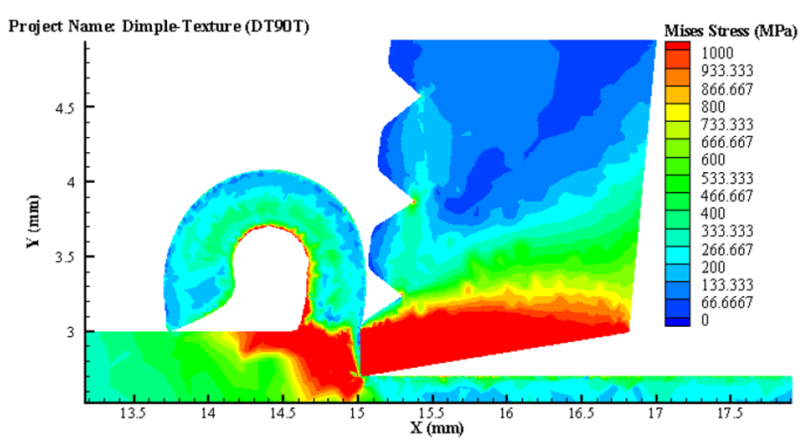

(c)

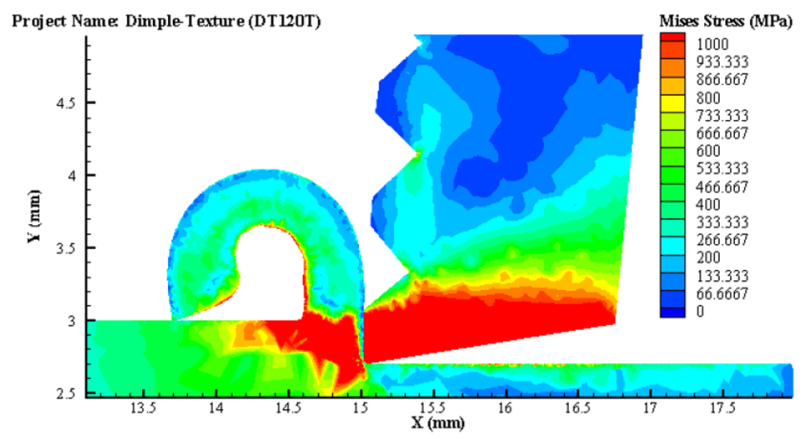

(e)

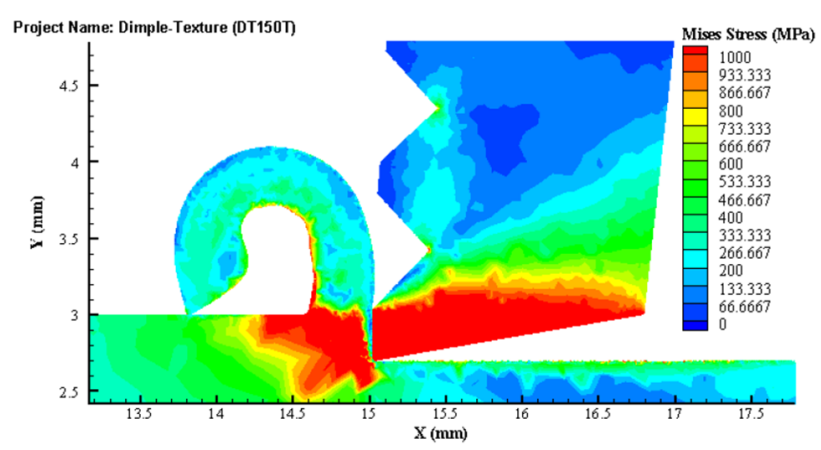

(g)

Fig. 8. Von-mises stresses for various inserts. (a) Non-texture regular insert. (b) $90 \mu \mathrm{m}$ circular dimple-texture insert. (c) $90 \mu \mathrm{m}$ triangular dimple-texture insert. (d) $120 \mu \mathrm{m}$ circular dimple-texture insert. (e) $120 \mu \mathrm{m}$ triangular dimple-texture insert. (f) $150 \mu \mathrm{m}$ circular dimple-texture insert. (g) $150 \mu \mathrm{m}$ triangular dimple-texture insert. 


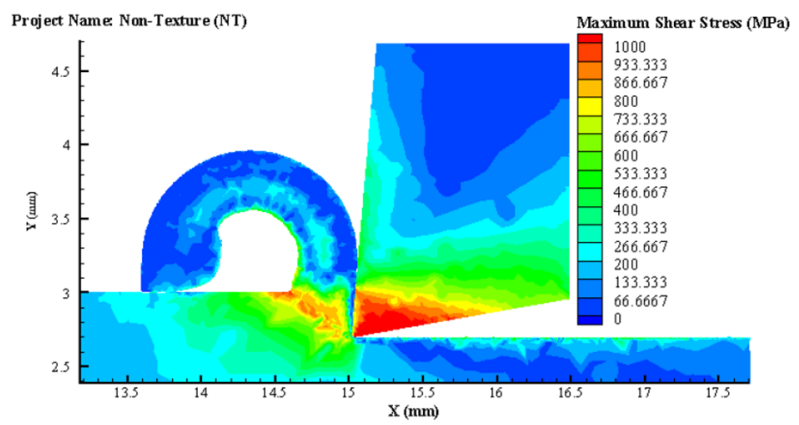

(a)

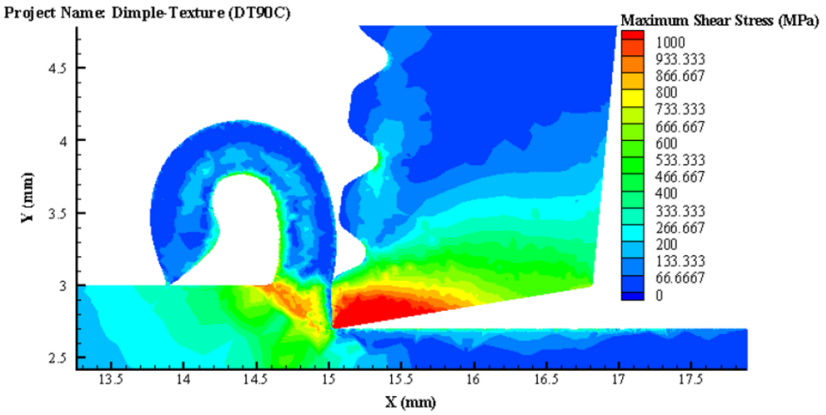

(b)

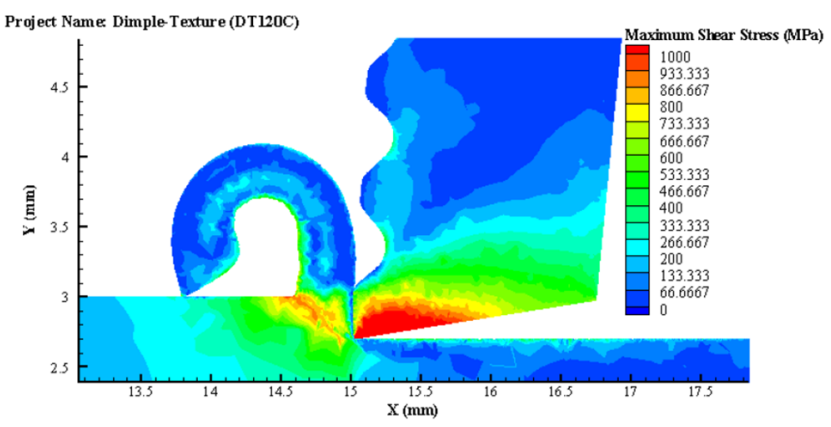

(d)

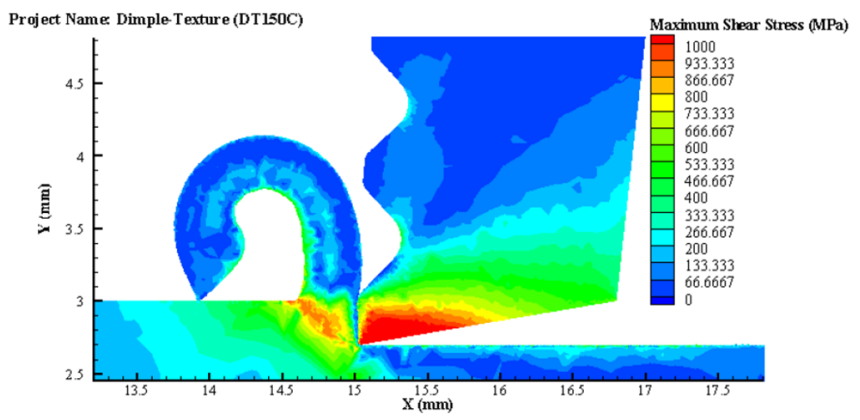

(f)

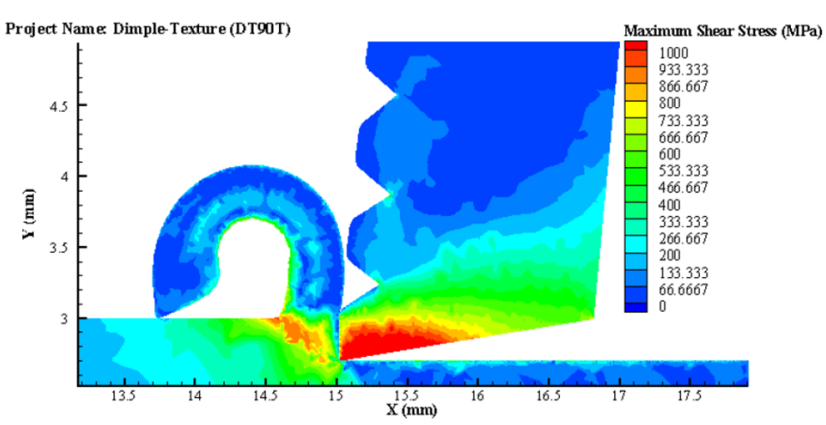

(c)

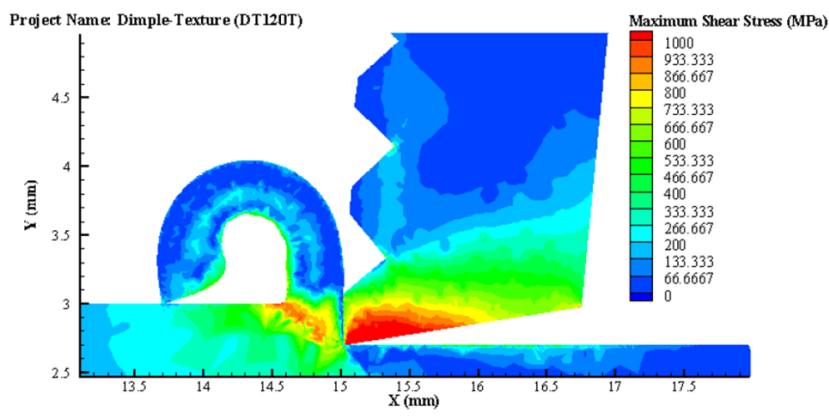

(e)

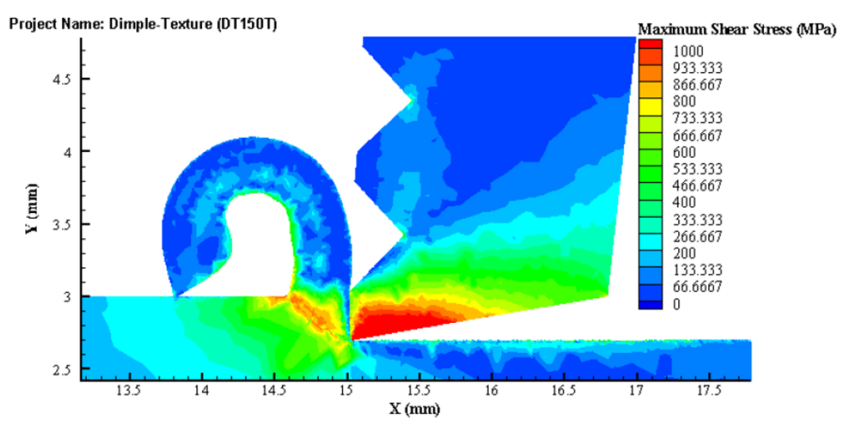

(g)

Fig. 9. Maximum shear stress distribution for various inserts. (a) Non-texture regular insert. (b) 90 um circular dimple-texture insert. (c) $90 \mu \mathrm{m}$ triangular dimple-texture insert. (d) $120 \mu \mathrm{m}$ circular dimple-texture insert. (e) 120 um triangular dimple-texture insert. (f) $150 \mu \mathrm{m}$ circular dimple-texture insert. (g) $150 \mu \mathrm{m}$ triangular dimple-texture insert. 


\subsection{Effect on cutting forces}

As shown in Figure 6, as compared to non-textured regular inserts, dimple-textured inserts exhibit much better performance, and cutting forces are reduced by about $50 \%$ for circular dimples and $10 \%$ for triangular dimples. When the micro-dimple size increases from $90 \mu \mathrm{m}$ to $120 \mu \mathrm{m}$, both cutting force components reduces by about $44 \%$ for the Force-X and $42 \%$ for the Force- $Y$ in the circular dimple category, $38 \%$ for the Force-X and $10 \%$ for the Force-Y in triangular dimple category. However, when micro-dimple size increases from $120 \mu \mathrm{m}$ to $150 \mu \mathrm{m}$, both cutting force components increase by about $48 \%$ for the Force-X and $44 \%$ for the Force- $\mathrm{Y}$ in the circular dimple category, $10 \%$ for the Force-X and $6 \%$ for the Force- $\mathrm{Y}$ in triangular dimple category. From Figure 6 , it is evident that the cutting force components for three dimples sizes in two dimple shape category are lower than that of regular non-textured inserts, which means that the micro-dimples are efficient in reducing two components of cutting forces for a $120 \mu \mathrm{m}$ circular dimple-texture inserts due to its optimal dimple geometry and reduced tribo-contact area. Similarly from previous research [22] discovered that using a dimple-textured insert of $120 \mu \mathrm{m}$ circular dimple size results in a $20 \%$ decrease in total cutting force when compared to non-textured inserts.

Figure 7 shows the cutting temperature distribution over the tool-work surfaces and peak temperature observed during dry machining for non-textured regular tool and dimple-texture tool with three dimples sizes in two dimple shape categories. It is evident that the circular shape dimple-texture tools exhibited in lower cutting temperature than non-textured and triangular shape dimpletexture tools. Compared with triangular shape dimpletexture and non-textured regular inserts, the circular shape dimple-texture inserts produced minimal contact area at the tribo-contact surfaces of the insert's chip and rack face, resulting in minimal friction and cutting temperature. Significantly, the $120 \mu \mathrm{m}$ circular dimple-texture inserts exhibit much better performance in cutting temperature reduction by about $8 \%$ with non-textured inserts and $5 \%$ with the triangular dimple category. The sharp-edged in the triangular shape micro-dimples may cause the increment in cutting temperature. The reduced tribocontact area of the tool-burr interfaces also reduced the heat transfer from work to insert. Furthermore, micro-dimples can act as heat transfer fins and provides the air gap between the chip and micro-dimple cavity to accelerate the heat dissipation rate.

Figure 8 shows the chip morphology. The von-mises stress distribution for non-textured regular tool and dimple-texture tool with three dimples sizes in two dimple shape categories after cutting force attained steady state. The micro-dimples appear to play two basic roles in chip morphology. First, they act as a micro-reservoir to retain the metal debris resulting in abrasive wear reduction at the tribo-contact surfaces. Second, micro-dimples at the tool-chip contacts resist the airflow resulting in pressure build-up between the tool-chip contact region. So, the tribo-contact area of the tool-chip interfaces much reduced when compared to regular non-texture inserts.
These two micro-dimples' two roles influence the chip morphology and stress distribution because of the reduced tribo-contact area of the tool-chip interfaces. It has been observed that the stress concentration around the cutting edge has a more significant influence on cutting tool failure, and excessive stress concentration may lead to insert tipping. Therefore, the Von-mises stress distributions and maximum stress distributions are shown in Figures 8 and 9, respectively. It can be observed that non-textured regular inserts produce higher stress concentration around the cutting edges. Even though the triangular dimple-texture inserts exhibit reduced tool-burr contact, the sharp edges in the triangular shaped microdimples produce higher stress concentration nearer to the cutting edges. The circular shape micro-dimples exhibit reduced tool-burr contact area and minimal stress concentration nearer to the cutting edges due to blended round surfaces. Furthermore, the circular shape micro-dimples effectively stress distribution throughout the tool-chip tribocontact area, instead of concentrated around the cutting edges. Therefore, the circular shape micro-dimples are effective in reducing the stress concentration and tool failure. Similarly from previous research [12] Von-Mises stress pattern was observed across the machining parameters, there is a gradual reduction in stress observed at greater cutting speed.

The insert wear rate is closely related to stress concentration and heat dissipation on the insert rack face based on the existing literature. The non-texture regular inserts and triangular-shaped dimple-texture inserts produce peak cutting temperature and higher stress concentration around the insert cutting edge, resulting in non-uniform and rapid insert wear. But, circular-shaped dimple-texture inserts produce comparatively lower cutting temperature and stress concentration, resulting in even and gradual insert wear.

\section{Conclusions}

In this paper, 2D FE simulation was used to compare the influences of dimple-textured inserts with non-textured regular inserts on the dry cutting of AISI H-13 steel. The significant research findings are:

- The circular-shaped dimple-textured inserts showed better machining performance that triangular-shaped dimple-texture and non-textured inserts in dry cutting of AISI H-13 steel. The 2D FE simulation also confirmed that circular-shaped dimple-textured inserts were efficient in chip breakage, reducing tool-burr contact area and abrasive wear in the tribo-contact interfaces, cutting temperature, and forces. Furthermore, the circular shape micro-dimples effective in stress distribution throughout the tool-chip tribo-contact area, reducing stress concentration and tool failure.

- The dimple-textured cutting tool influences reducing cutting forces as compared with non-textured inserts. The decremental order of cutting force generated during dry machining as follows: Non-texture regular tool > Triangular shaped dimple-textured tool $>$ Circular shaped dimple-textured tool. 
- Circular shaped dimple-textured tool (micro-dimple size of $120 \mu \mathrm{m}$, depth of $20 \mu \mathrm{m}$, a distance of $135 \mu \mathrm{m}$, and density area of $35 \%$ ) exhibits much better performance.

- The minimal cutting temperature was observed in the circular shaped dimple-textured tool. The micro-dimples can act as a heat transfer fins and provide the air gap between the chip and micro-dimple cavity to accelerate the heat dissipation rate.

\section{References}

1. M.S. Dennison, M.M. Umar, Data-set collected during turning operation of AISI 1045 alloy steel with green cutting fluids in near dry condition, Data Brief 32, 106215 (2020)

2. M.S. Dennison, N.M. Sivaram, D. Barik, S. Ponnusamy, Turning operation of AISI 4340 steel in flooded, near-dry and dry conditions: a comparative study on tool-work interface temperature, Mech. Mech. Eng. 23, 172-182 (2019)

3. R. Duan, J. Deng, S. Lei, D. Ge, Y. Liu, X. Li, Effect of derivative cutting on machining performance of micro textured tools, J. Manufactur. Process. 45, 544-556 (2019)

4. S. Durairaj, J. Guo, A. Aramcharoen, S. Castagne, An experimental study into the effect of micro-textures on the performance of cutting tool, Int. J. Adv. Manufactur. Technol. 98, 1011-1030 (2018)

5. K.K. Gajrani, S. Suresh, M.R. Sankar, Environmental friendly hard machining performance of uncoated and $\mathrm{MoS}_{2}$ coated mechanical micro-textured tungsten carbide cutting tools, Tribol. Int. 125, 141-155 (2018)

6. Z. Kang, Y. Fu, Y. Chen, J. Ji, H. Fu, S. Wang, R. Li, Experimental investigation of concave and convex microtextures for improving anti-adhesion property of cutting tool in dry finish cutting, Int. J. Precis. Eng. Manufactur. Green Technology 5, 583-591 (2018)

7. M.A. Khan, K. Gupta, A study on machinability of nickel based superalloy using micro-textured tungsten carbide cutting tools, Mater. Res. Express 7, 016537 (2020)

8. Y.S. Lian, C.L. Mu, M. Liu, H.F. Chen, B. Yao, Threedimensional numerical simulation of soft/hard compositecoated textured tools in dry turning of AISI 1045 steel, Adv. Manufactur. 7, 133-141 (2019)

9. G. Liu, C. Huang, R. Su, T. Özel, Y. Liu, L. Xu, 3D FEM simulation of the turning process of stainless steel $17-4 \mathrm{PH}$ with differently texturized cutting tools, Int. J. Mech. Sci. 155, 417-429 (2019)

10. G. Liu, T. Özel, J. Li, D. Wang, S. Sun, Optimization and fabrication of curvilinear micro-grooved cutting tools for sustainable machining based on finite element modelling of the cutting process, Int. J. Adv. Manufactur. Technol. 110, 1327-1338 (2020)

11. J. Ma, N.H. Duong, S. Lei, Numerical investigation of the performance of microbump textured cutting tool in dry machining of AISI 1045 steel, J. Manufactur. Process. 19, 194-204 (2015)

12. K. Gobivel, K.S. Vijaysekar, G. Prabhakaran, Impact of cutting parameters on machining of Ti-6Al-4V alloy: an experimental and FEM approach, Int. J. Simul. Multidiscip. Des. Optim. 12, 2 (2021)

13. R. Chaari, M. Abennadher, J. Louati, M. Haddar, Mathematical methodology for optimization of the clamping forces accounting for workpiece vibratory behaviour, Int. J. Simul. Multidiscipl. Des. Optim. 5, A13 (2014)

14. S.K. Mishra, S. Ghosh, S. Aravindan, 3D finite element investigations on textured tools with different geometrical shapes for dry machining of titanium alloys, Int. J. Mech. Sci. 141, 424-449 (2018)

15. S.K. Mishra, S. Ghosh, S. Aravindan, Performance of laser processed carbide tools for machining of Ti6Al4V alloys: a combined study on experimental and finite element analysis, Precis. Eng. 56, 370-385 (2019)

16. M.S. Sawant, N.K. Jain, I.A. Palani, Influence of dimple and spot-texturing of HSS cutting tool on machining of Ti-6Al-4V, J. Mater. Process. Technol. 261, 1-11 (2018)

17. R. Singh, J.S. Dureja, M. Dogra, Performance evaluation of textured carbide tools under environment-friendly minimum quantity lubrication turning strategies, J. Braz. Soc. Mech. Sci. Eng. 41, 87 (2019)

18. G. Vignesh, D. Barik, P. Ragupathi, S. Aravind, Experimental analysis on turning of AISI 4340 steel using non-textured, dimple textured and $\mathrm{MoS}_{2}$ coated dimple textured carbide cutting inserts at the rack surface, Mater. Today 33, 2616-2620 (2020)

19. G. Vignesh, M. Prakash, M.D. Selvam, P. Ragupathi, Frictional performance of dimpled textured surfaces on a frictional pair: an experimental study. I-Manager's, J. Mech. Eng. 8, 18-24 (2018)

20. Y. Wei, R. Tomkowski, A. Archenti, Numerical study of the influence of geometric features of dimple texture on hydrodynamic pressure generation, Metals 10, 361 (2020)

21. N. Zhang, F. Yang, G. Liu, Cutting performance of microtextured WC/Co tools in the dry cutting of Ti-6Al-4V alloy, Int. J. Adv. Manufactur. Technol. 1-13 (2020)

22. G. Vignesh, D. Barik, S. Aravind, P. Ragupathi, M. Arun, An experimental study on machining of AISI H-13 steel using dimple-textured and non-textured tungsten carbide cutting tools, IOP Conf. Ser. Mater. Sci. Eng. 1017, 012$021(2021)$

Cite this article as: Ganesan Vignesh, Debabrata Barik, Samraj Aravind, Ponnusamy Ragupathi, Munusamy Arun, Numerical investigation of dimple-texturing on the turning performance of hardened AISI H-13 steel, Int. J. Simul. Multidisci. Des. Optim. 13, $10(2022)$ 